\section{Use of Crop Water Stress Index to Schedule Irrigation of Freeway Landscape Plants}

\author{
Alexander X. Niemiera ${ }^{1}$ and Monika Goy ${ }^{2}$ \\ Division of Agriculture, Arizona State University, Tempe, AZ 85287
}

Additional index words. xerophytic plants, leaf temperature; infrared thermometer

Abstract. A study was conducted to determinethe feasibility of using crop water stress index (CWSI) to schedule irrigation of eight species of freeway landscape plants, Acacia redolens B.R. Maslin, Acacia salicina Lindl., Caesalpinia pulcherrima Sw., Cassia nemophila A. Cunn. ex Vogel, Cercidium floridum Benth., Eucalyptus microtheca F.J. Muell., Nerium oleander L., and Prosopis chilensis Mol. Nerium oleander and C. pulcherrima were suited to the use of the CWSI, tolerated repeated exposures to CWSI values of 0.6, and remained aesthetically acceptable. Irrigation of $N$. oleander via the CWSI resulted in a $19 \%$ reduction in water use, compared to the conventional method. CWSI data of other species were too variable, and, thus, irrigation could not be scheduled by CWSI values. Variability was attributed, in part, to lack of a dense canopy, which is necessary to fill the view of the infrared thermometer.

Decreasing groundwater supplies in the arid southwestern United States have brought about legislation, such as the Arizona Groundwater Management Act of 1980, that mandates water conservation by municipalities. One available avenue of water conservation is the efficient irrigation of city landscape plants, since such plants in the Southwest are routinely irrigated, resulting in large water expenditures. For example, the landscape water use per day for a single housing unit in the Phoenix metropolitan area can be as much as 500 liters. day $^{-1}$ (Arizona Department of Water Resources, 1988). The goal of efficient landscape irrigation is to supply plants with the minimum amount of water that will maintain

Received for publication 7 Feb. 1989. This work was supported by a grant from the Arizona Dept. of Transportation. The cost of publishing this paper was defrayed in part by the payment of page charges. Under postal regulations, this paper therefore must be hereby marked advertisement solely to indicate this fact.

${ }^{1}$ Assistant Professor. Current address: Dept. of Horticulture, Virginia Polytechnic Institute and State Univ., Blacksburg, VA 24061.

${ }^{2}$ Graduate Student. terns for irrigating landscape plants use time clocks that signal the application of water at them in an aesthetically acceptable condition. However, plant species and their size, as well as edaphic and climatic factors, affect the amount of water required. Most sys- set intervals, regardless of the-plants' need for water. However, a need exists for a simple, reliable method for timing irrigations that uses the plants' water requirements as the signal to irrigate. Tanner (1963) suggested use of plant temperatures to assess crop water deficits and infrared thermometry as the most likely tool for this purpose. Subsequent studies confirmed the advantages of the noninvasive infrared thermometer (IRT) over directcontact sensors (Berliner et al., 1984; Walker and Hatfield, 1983), and Sachs et al. (1975) suggested that leaf temperatures measured with an IRT could be used to schedule irrigation of landscape plants.

Crop water stress index (CWSI) uses leaf temperature and vapor pressure deficit (VPD) data to determine a relative degree of plant water stress. The index is based on the fact that transpirational cooling reduces leaf temperature relative to air temperature; the reduction being greater at relatively high VPD values (low moisture content) compared to low VPD values. Leaf temperature increases when the supply of water to a plant limits transpiration and when radiant energy is not dissipated via evaporation.

Empirical observations (Idso et al., 1981a) establishing CWSI resuited in the discovery that, for a well-watered crop, there exists an inverse, linear relationship between the foliage

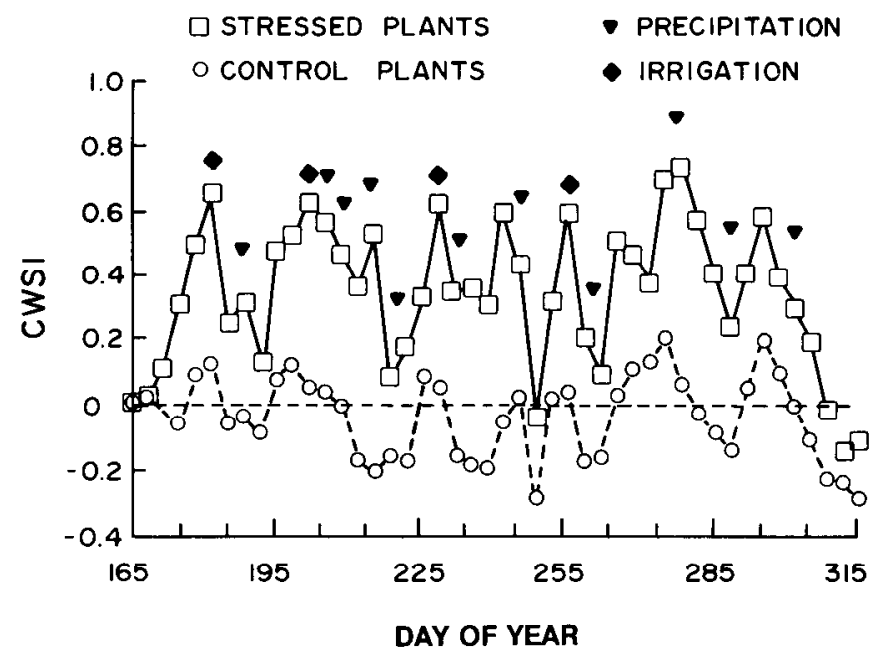

Fig. 1. Mean CWSI values of three control plants of Nerium oleander and three water-stressed plants over time. 
Table 1. Baseline equations for Nerium oleander and Caesalpinia pulcherrima.

\begin{tabular}{lccc}
\hline \hline Month & $\begin{array}{c}\text { Irrigation } \\
\text { (liters.day }^{-1} \text { ) }\end{array}$ & Baseline & $r$ Value $^{2}$ \\
\hline March & 24 & Nerium oleander & \\
April & 43 & $\mathrm{~T}_{\mathrm{f}}-\mathrm{T}_{\mathrm{a}}=-1.50+0.39 \mathrm{VPD}$ & 0.37 \\
June & 114 & $\mathrm{~T}_{\mathrm{f}}-\mathrm{T}_{\mathrm{a}}=0.75-0.60 \mathrm{VPD}$ & 0.49 \\
October & 114 & $\mathrm{~T}_{\mathrm{f}}-\mathrm{T}_{\mathrm{a}}=4.27-1.59 \mathrm{VPD}$ & 0.89 \\
& $\mathrm{~T}_{\mathrm{f}}-\mathrm{T}_{\mathrm{a}}=1.40-0.95 \mathrm{VPD}$ & 0.74 \\
May & 43 & Caesalpinia pulcherrima & 0.15 \\
June & 114 & $\mathrm{~T}_{\mathrm{f}}-\mathrm{T}_{\mathrm{a}}=-1.40-0.16 \mathrm{VPD}$ & 0.65 \\
June & 150 & $\mathrm{~T}_{\mathrm{f}}-\mathrm{T}_{\mathrm{a}}=1.83-1.14 \mathrm{VPD}$ & 0.87 \\
October & 114 & $\mathrm{~T}_{\mathrm{f}}-\mathrm{T}_{\mathrm{a}}=2.23-1.34 \mathrm{VPD}$ & 0.15 \\
\hline
\end{tabular}

${ }^{2}$ Monthly $r$ values and regression equations were calculated using a minimum of 1000 observations $\left(T_{f}\right.$ $\left.-\mathrm{T}_{\mathrm{a}}\right)$.

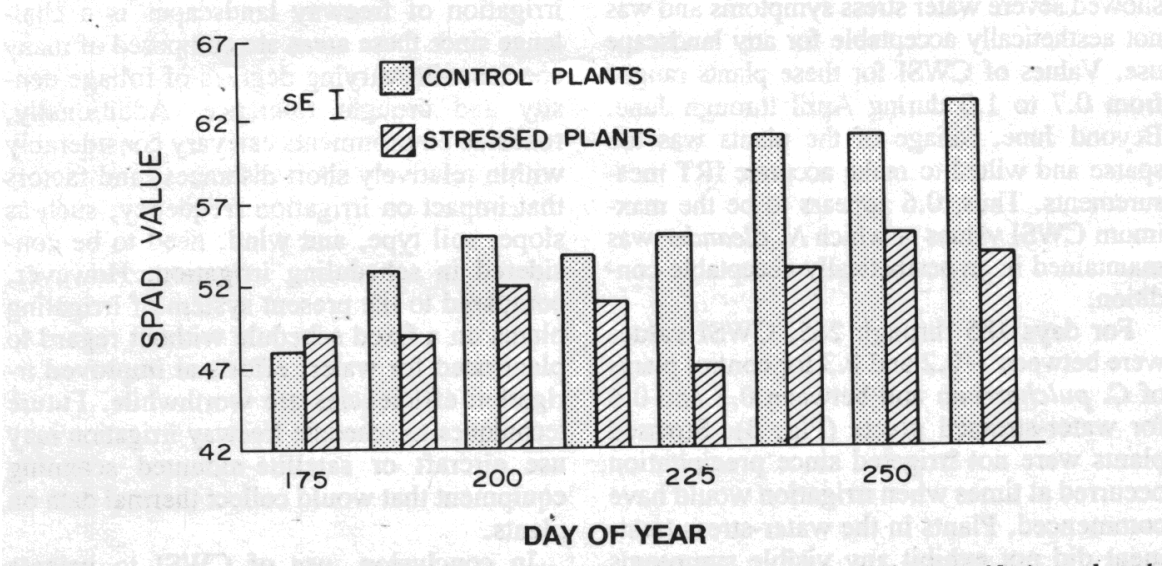

Fig. 2. Mean relative chlorophyll content (SPAD value) of three control plants at Nerium oleander and three water-stressed plants over time, $n=9$. Bars indicate \pm 1 SD.

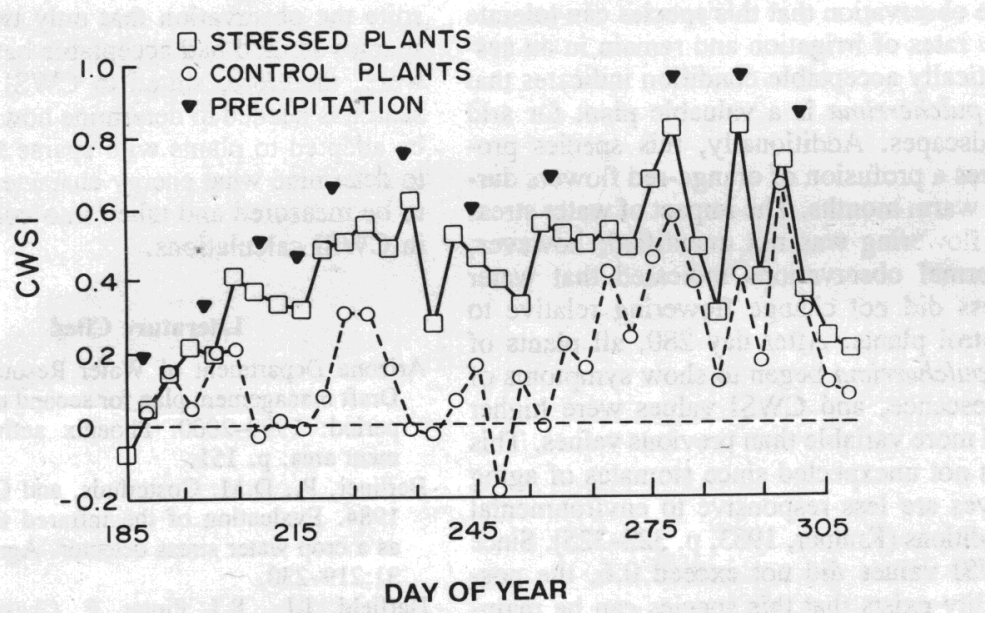

Fig. 3. Mean CWSI values of three control plants of Caesalpinia pulcherrima and three water-stressed plants over time.

minus air temperature differential $\left(\mathrm{T}_{\mathrm{f}}-\mathrm{T}_{\mathrm{a}}\right)$ (y axis) and VPD (x axis). This line, termed the baseline, is crop-specific and represents the lower limit (maximum transpiration) of the CWSI. Calculation and discussion of the CWSI are reviewed by Idso et al. (1982a). The index, which ranges from 0 (no stress) to 1.0 (maximum stress) has been shown to be significantly correlated with net photosynthesis and soil water content in the root zone of cotton (Gossypium hirsutum L.) (Idso et al., 1982b; Jackson et al., 1981), plant water potential in wheat (Triticum durum Desf.) (Idso et al., tion of xerophytic landscape plants. The objective of this research was to determine if CWSI could be used to schedule irrigation of desert freeway landscapes.

There were eight species of landscape plants in the study: Acacia redolens, Acacia salicina, Caesalpinia pulcherrima, Cassia nemophila, Cercidium floridum, Eucalyptus microtheca, Nerium oleander, and Prosopis chilensis. Nine mature plants per species were selected on the basis of uniformity in size, form, and state of vigor. Microhabitat of the study area was also taken into consideration so that a minimum amount of variability, with regard to location as well as appearance, existed among plants of a species. The soil surface was covered with a decomposed granite mulch. The study was conducted from Sept. 1987 through Oct. 1988 along the Superstition freeway in Mesa, Ariz. Soil samples were taken throughout the study area and tested for soil texture, $\mathrm{pH}$, bulk density, salt content, and moisture-holding capacity. Results (data not shown) indicated relatively uniform soil characteristics.

Foliage temperatures were obtained with a 3-degree field of view IRT (model $112 \mathrm{C}$, Everest Interscience, Tustin, Calif.). The IRT was aimed at plants with the sun at the observer's back so that a maximum amount of foliage was illuminated. IRT measurements of shrubs were made at a distance of 1 to 2 $m$ from the upper half of the canopy. Trees were measured at a distance of 1 to $2 \mathrm{~m}$, with the IRT pointed at foliage $\approx 2 \mathrm{~m}$ above ground level. The IRT was aimed at plants in a manner to avoid flowers or seed pods, since reproductive structures exposed to the sun are warmer than leaves (Hatfield et al., 1984). Before and after each use, IRT readings from a portable source calibration unit (Everest Interscience) were made to correct temperatures displayed by the IRT. Concomitant with IRT measurements, wet and dry bulb temperature measurements were made with a battery-powered psychrometer (Psychro-Dyne, Cole-Parmer Instrument Co., Chicago, Ill.). The psychrometer and source calibration unit were positioned in the shade, $1 \mathrm{~m}$ above ground, within $50 \mathrm{~m}$ of plants being monitored. Shrubs and trees were irrigated by a drip system equipped with single- and multiple-port pressure compensating emitters, respectively. There were two phases in the study. In phase 1, baseline data were taken for all species to determine if a significant relationship, Pearson's correlation coefficient $(r)>0.6$ (0.05 level), existed between air VFD and $T_{f}-T_{a}$. In phase 2 , species that exhibited such a relationship were irrigated at targeted CWSI values.

Phase 1. The average of 10 foliage temperature measurements per plant (nine plants per species) taken at 30-min intervals from 0800 to 1500 HR was used for baseline calculations. Since some species were winterdeciduous, data collection commenced at the time when there was a sufficient amount of foliage to fill the view of the IRT.

Phase 2. Species with $r$ values $>0.6$ were subjected to water stress treatments. Three control plants per species were maintained 
at a CWSI value of 0 to 0.2 by irrigation. Stressed plants (six per species) were irrigated when CWSI was in the range of 0.5 to 0.7. Irrigation of stressed plants ceased when values were in the range of 0 to 0.2 . Ten IRT measurements per plant (controls and stressed) were made about three times per week between 1130 and 1330 HR. A preliminary experiment was conducted to determine the influence of time of day on CWSI values. Results of this experiment (data not shown) showed that CWSI values of waterstressed plants were greater at $1330 \mathrm{HR}$ than at $1230 \mathrm{HR}$. In contrast, CWSI values of control plants were essentially the same at both times. Therefore, each species had its own temperature measurement time. A computer program (provided by USDA, ARS, U.S. Water Conservation Laboratory, Phoenix, Ariz.) was used to calculate CWSI values according to Idso et al. (1981a). The program was adapted for individual species by using respective baseline slope and intercept values.

Plant physical appearance was monitored weekly. Criteria included leaf color, presence of wilt symptoms, and overall aesthetic acceptance. Relative leaf chlorophyll content was measured for plants of $N$. oleander using a SPAD 501 chlorophyll meter (Minolta Co., Ramsey, N.J.). A high correlation between SPAD 501 readings and leaf chlorophyll content, expressed on a leaf-area basis, has been reported (Marquard and Tipton, 1987). Leaves of other species did not have a large enough surface area to facilitate chlorophyll measurements with this meter.

Initially, plants were irrigated according to an existing freeway schedule. However, lack of significant baseline relationships between $T_{f}-T_{a}$. and VPD suggested that plants were not receiving sufficient water to achieve maximum transpiration rates. For two species, baseline $r$ values increased significantly with increasing irrigation amounts (Table 1). The baseline $r$ value for the evergreen $\mathrm{N}$. oleander was 0.37 in March at an irrigation rate of 24 liters $\cdot d_{a y}{ }^{-1}$. Correlation increased with an increase in irrigation rate to an $r$ value of 0.89 obtained in June. Similar to $N$. oleander, $r$ values for the winter-deciduous $C$. pulcherrima increased from 0.15 in May to 0.87 in June as irrigation rate increased (Table 1). Baseline $r$ values obtained in June for these two species indicated that they were suited to the use of the CWSI, and plants were subsequently subjected to stress treatments. Baseline $r$ values of nonstressed control plants of both species decreased in October. The decrease was much greater for C. pulcherrima than $N$. oleander. This was most likely due to leaf senescence of the deciduous Caesalpinia.

CWSI values for control plants of $N$. oleander ranged from -0.2 to 0.2 , whereas CWSI values for water-stressed plants reached the targeted range of 0.5 to 0.7 eight times during the study (Fig. 1). CWSI values decreased following irrigation or precipitation. Beyond day 212, relative chlorophyll content of stressed plants was less than that of control plants (Fig. 2). Visible stress symp- toms were not evident until plants reached the CWSI value of 0.5 for the fourth time (day 229). At about that time, plants exhibited dull green leaves, stunted growth, and sparse foliage. Despite this decrease in plant quality, we regarded overall plant appearance beyond day 229 as acceptable for freeway landscapes, based on the appearance of plants being viewed by automobile passengers at freeway speeds. At the end of the study, stressed plants were $\approx 25 \%$ shorter than controls. This decrease could be viewed as an advantage since these plants would require less pruning than plants on a regular irrigation schedule. A group of $N$. oleander, located in the vicinity of the study area, but not initially subject to treatment, showed severe water stress symptoms and was not aesthetically acceptable for any landscape use. Values of CWSI for these plants ranged from 0.7 to 1.0 during April through June. Beyond June, foliage of the plants was too sparse and wilted to make accurate IRT measurements. Thus, 0.6 appears to be the maximum CWSI values at which $N$. oleander was maintained in an aesthetically acceptable condition.

For days 185 through 265, CWSI values were between -0.2 and 0.3 for control plants of $C$. pulcherrima and between 0.3 and 0.6 for water-stressed plants (Fig. 3). Stressed plants were not irrigated since precipitation occurred at times when irrigation would have commenced. Plants in the water-stress treatment did not exhibit any visible symptoms of stress and could not be differentiated from control plants on the basis of appearance. The observation that this species can tolerate low rates of irrigation and remain in an aesthetically acceptable condition indicates that C. pulcherrima is a valuable plant for arid landscapes. Additionally, this species produces a profusion of orange-red flowers during warm months. The impact of water stress on flowering was not quantified; however, informal observations indicated that water stress did not change flowering relative to control plants. After day 280, all plants of C. pulcherrima began to show symptoms of senescence, and CWSI values were higher and more variable than previous values. This was not unexpected since stomates of aging leaves are less responsive to environmental conditions (Kramer, 1983, p. 322-325). Since CWSI values did not exceed 0.6 , the possibility exists that this species can be maintained in an acceptable condition at values $>0.6$.

Acceptable baseline $r$ values for $A$. redolens, A. salicina, C. floridum, C. nemophila, E. microtheca, and $P$. chilensis could not be obtained due to variable $\mathrm{T}_{\mathrm{f}}-\mathrm{T}_{\mathrm{a}}$ readings (data not shown) and therefore were not subjected to stress treatments. The most probable reason for this occurrence may be lack of a sufficiently dense canopy. Canopies of these species were less dense than $N$. oleander and $C$. pulcherrima, which made it difficult to fill the view of the IRT with foliage. An IRT measurement on these species would then yield a temperature value that included soil or other background infrared energy. Other factors that may have been responsible for variable baseline readings are advective and radiant energy exchange phenomena that occur around plants and directly affect foliage temperature.

Nerium oleander irrigated according to the CWSI received $19 \%$ less water during summer months than plants irrigated according to standard freeway operating procedure. For a 1.7-km section of freeway in Mesa, Ariz., planted with 815 plants of $N$. oleander, this reduction would result in a savings of $\approx 175,000$ liters of water during summer months. Considering the hundreds of kilometers of freeways in Arizona landscaped with $N$. oleander, this technique would result in significant water conservation. Yet, irrigation of freeway landscapes is a challenge since these areas are composed of many species with varying degrees of foliage density and drought tolerance. Additionally, roadside environments can vary considerably within relatively short distances, and factors that impact on irrigation frequency, such as slope, soil type, and wind, need to be considered in scheduling irrigation. However, compared to the present system of irrigating plants on a fixed schedule without regard to plant need for water, efforts at improved irrigation efficiencies are worthwhile. Future techniques to schedule freeway irrigation may use aircraft or satellite-mounted scanning equipment that would collect thermal data on plants.

In conclusion, use of CWSI to irrigate freeway and other landscapes has potential to conserve significant amounts of water, despite the observation that only two of eight species studied had acceptable baselines and were, therefore, suited to CWSI. More research is needed to determine how CWSI can be adapted to plants with sparse foliage and to determine what energy characteristics need to be measured and taken into consideration in CWSI calculations.

\section{Literature Cited}

Arizona Department of Water Resources. 1988. Draft management plan for second management period: 1990-2000. Phoenix active management area. p. 151.

Berliner, P., D.M. Oosterhuis, and G.C. Green. 1984. Evaluation of the infrared thermometer as a crop water stress detector. Agr. For. Met. $31: 219-230$

Hatfield, J.L., P.J. Pinter, E. Chasseray, C.E. Erza, R.J. Reginato, S.B. Idso, and R.D. Jackson. 1984. Effects of panicles on infrared thermometer measurements of canopy temperature in wheat. Agr. For. Met. 32:97-105.

Idso, S.B., R.D. Jackson, P.J. Pinter, Jr., R.J. Reginato, and J.L. Hatfield. 1981a. Normalizing the stress-degree-day parameter for environmental variability. Agr. Met. 24:45-55.

Idso, S.B., R.J. Reginato, R.D. Jackson, and P.J. Pinter, Jr. 1981b. Measuring yield-reducing plant water potential depressions in wheat by infrared thermometry. Irr. Sci. 2:205-212.

Idso, S.B. 1982. Non-water-stressed baselines: A key to measuring and interpreting plant water stress. Agr. Met. 27:59-70.

Idso, S.B., R.J. Reginato, and S.M. Farah. 1982a. Soil-atmosphere-induced plant water stress in cotton as inferred from foliage temperatures. Water Resource Res. 18:1143-1148. 
Idso, S.B., R.J. Reginato, and J.W. Radin. 1982b. Leaf diffusion resistance and net photosynthesis in cotton as related to a foliage temperature based plant water stress index. Agr. Met. 27:27-34.

Jackson, R.D., S.B. Idso, R.J. Reginato, and P.J. Pinter, Jr. 1981. Canopy temperature as a crop water stress indicator. Water Resources Res. 17:1133-1138

Kramer, P.J. 1983. Water relations of plants. Academic, New York.
Marquard, R.D. and J.L. Tipton. 1987. Relationship between extractable chlorophyll and an in situ method to estimate leaf greenness. HortScience 22:1327.

Nakayama, F.S. and D.A. Bucks. 1984. Crop water stress index, soil water, and rubber yield relations for the guayule plant. Agron. J. 76:791794.

O'Toole, J.C., N.C. Turner, O.P. Namuco, M. Ding-kuh, and K.A. Gomez. 1984. Compari- son of some crop water stress measurement methods. Crop Sci. 24:1121-1128.

Sachs, R.M., T. Kretchun, and T. Mock. 1975. Minimum irrigation requirements for landscape plants. J. Amer. Soc. Hort. Sci. 100:499-502. Tanner. C.B. 1963. Plant temperatures. Agron. J. 55:210-211.

Walker, G.K. and J.L. Hatfield. 1983. Stress measurement using foliage temperatures. Agron. J. 75:623-629. 